\title{
Joint statement on EPA proposed rule and public availability of data
}

\author{
Jeremy Berg ${ }^{a, 1}$, Philip Campbell ${ }^{b}$, Veronique Kiermer ${ }^{c}$, Natasha Raikhel ${ }^{\mathrm{d}, e}$, and Deborah Sweet ${ }^{f}$
}

We are writing in response to a proposed rule announced by the Environmental Protection Agency (EPA) in a 24 April 2018 press release (1). The release reads, "The rule will ensure that the regulatory science underlying Agency actions is fully transparent, and that underlying scientific information is publicly available in a manner sufficient for independent validation."

Data sharing is a feature that contributes to the robustness of published scientific results. Many peerreviewed scientific journals have recently adopted policies that support data sharing, consistent with the Transparency and Openness Promotion (TOP) standards. These standards, however, recognize the array of workflows across scientific fields and make the case for data sharing at different levels of stringency; in not every case can all data be fully shared. Exceptional circumstances, where data cannot be shared openly with all, include data sets featuring personal identifiers.

We support maintaining the rigor of research published in our journals and increasing transparency regarding the evidence on which conclusions are based. As part of these goals, we require that all data used in the analysis must be available to any researcher for purposes of reproducing or extending the analysis. Importantly, the merits of studies relying on data that cannot be made publicly available can still be judged. Reviewers can have confidential access to key data and, as a core skill, scientists are trained in assessing research publications by judging the articulation and logic of the research design, the clarity of the description of the methods used for data collection and analysis, and appropriate citation of previous results.

It does not strengthen policies based on scientific evidence to limit the scientific evidence that can inform them; rather, it is paramount that the full suite of relevant science vetted through peer review, which includes ever more rigorous features, inform the landscape of decision making. Excluding relevant studies simply because they do not meet rigid transparency standards will adversely affect decisionmaking processes.

1 US Environmental Protection Agency (2018) News Releases, "EPA Administrator Pruitt proposes rule to strengthen science used in EPA regulations." Available at https://www.epa.gov/newsreleases/epa-administrator-pruitt-proposes-rule-strengthen-science-used-eparegulations.

\footnotetext{
${ }^{a}$ Editor-in-Chief, Science family of journals, Washington, DC 20005; ${ }^{b}$ Editor-in-Chief, Nature, London, N1 9XW, United Kingdom; ${ }^{2}$ Executive Editor, Public Library of Science (PLOS) Journals, San Francisco, CA 94111; 'Interim Editor-in-Chief, PNAS, Washington, DC 20001; ${ }^{\circledR}$ Distinguished Professor of Plant Biology, University of California, Riverside, CA 92507; and 'Vice President of Editorial, Cell Press, and Acting Editor-in-Chief, Cell, Cambridge, MA 02139

Editor's note: This statement is being published simultaneously as a letter in Science [Berg J, et al. (2018) Science, https://doi.org/10.1126/science. aau0116], which should be the primary citation. It will be disseminated by all the publications represented by the signatories.

${ }^{1}$ To whom correspondence should be addressed. Email: jberg@aaas.org.

Published online May 3, 2018.
} 